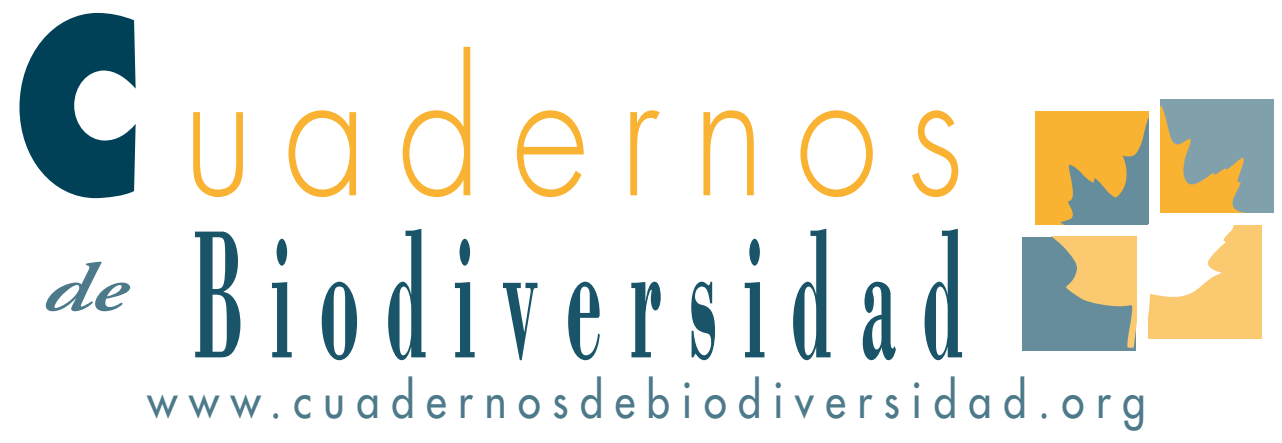

\title{
NOTICIAS
}

\section{La Estación Biológica de Torretes y sus zonas visitables reciben el reconocimiento como Jardín Botánico}

Recientemente, la Estación Biológica de Torretes ha recibido el respaldo por unanimidad de la Asociación Ibero Macaronésica de Jardines Botánicos (AIMJB) para ser admitida como miembro de pleno derecho de dicha Asociación. Esto implica que ha pasado a tener la consideración de Jardín Botánico, al mismo nivel que instituciones tan prestigiosas como el Jardín Botánico de Valencia o el Real Jardín Botánico de Madrid.

Supone un paso muy importante para la consolidación del proyecto de la Estación Biológica, que ha sido reñido y competitivo, pues de las tres candidaturas que concurrieron, solamente nuestra Estación fue admitida por la AIMJB. Tras este reconocimiento la Estación Biológica de Torretes se convierte en el segundo Jardín Botánico de la Comunidad Valen- ciana y el primero y único de la provincia de Alicante y además en un referente nacional e internacional en la conservación de la diversidad vegetal.

Esto es el fruto de casi ya diez años de trabajo de todo un equipo de colaboradores que han logrado transformar una finca abandonada en un espacio singular de investigación, formación y conservación de la naturaleza mediterránea, con una importante orientación hacia la etnobotánica y la cultura tradicional.

La consideración como Jardín Botánico es sin duda un galardón, pero al mismo tiempo un reto y una nueva exigencia para mantener y superar los estándares de calidad del resto de Jardines Botánicos de España y Portugal.

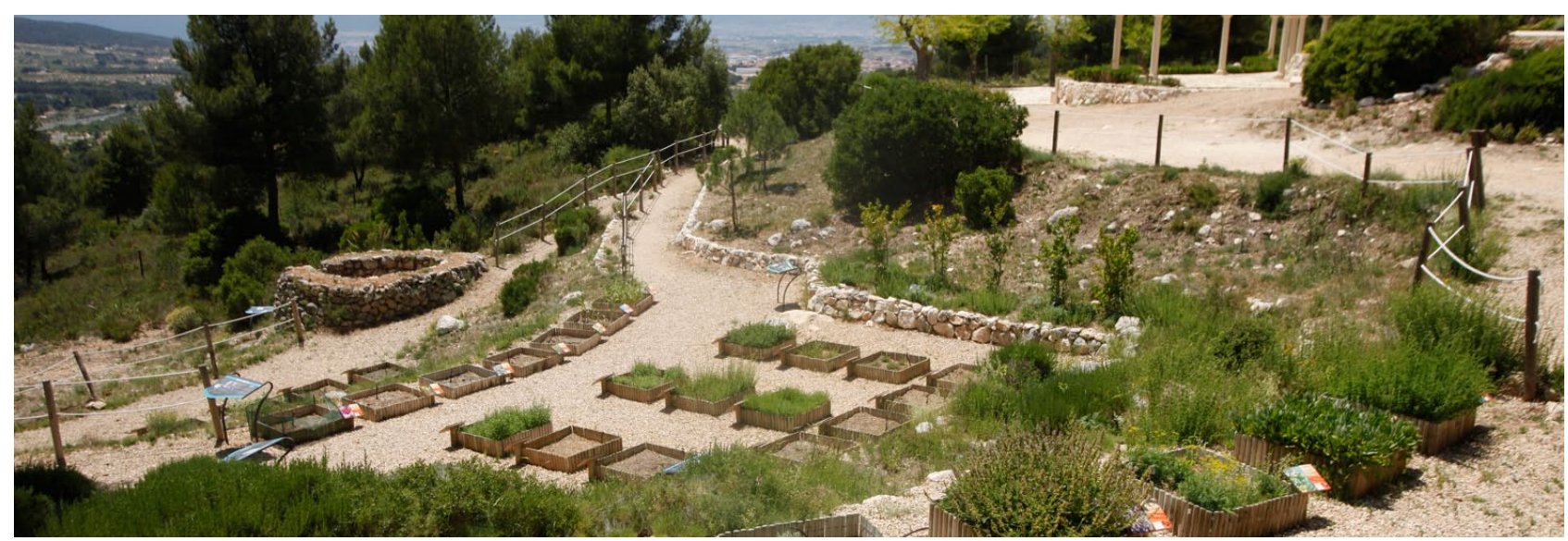

Foto: Rincón plantas medicinales 


\section{RESEÑA HISTÓRICA}

La Estación Biológica de Torretes es una unidad de investigación y divulgación científica adscrita al Instituto Universitario de la Biodiversidad CIBIO, que se crea como resultado de la cooperación entre el Excmo. Ayuntamiento de Ibi y la Universidad de Alicante. Con ese propósito el 29 de marzo de 2003 se estableció un acuerdo entre la Universidad de Alicante y el Excmo. Ayuntamiento de Ibi para el desarrollo de la investigación, la conservación y la divulgación científica de la Biodiversidad mediterránea, tanto la procedente de los ecosistemas naturales, como de los Agroecosistemas tradicionales domesticados por el hombre. Dicho convenio fue ratificado y ampliado, por otro suscrito el 11 de enero de 2006 entre ambas partes, con un segundo convenio con una vigencia de 50 ańos prorrogables, por el cual el Excmo. Ayuntamiento de Ibi manteniendo la propiedad de los terrenos, cedió en uso y dirección los mismos a la Universidad de Alicante, a través de su Instituto Universitario de Investigación CIBIO y se estableció un compromiso de cofinanciación por partes iguales.

En dicho convenio además, se incluyó en condiciones similares el Museo de la Biodiversidad, ubicado en el centro de la población de Ibi, cuyos contenidos, programaciones didácticas y visitas guiadas, son también coordinados desde el CIBIO.

\section{SITUACIÓN FÍSICA}

La Estación Biológica se encuentra situada al Norte de la Provincia de Alicante, en el término municipal de Ibi, abarca de los $900-1100 \mathrm{~m}$ de altitud y su origen es una antigua finca de secano denominada "Les Torretes", sita en la cara sur del Parque Natural del Carrascal de la Font Roja. Cuenta con una superficie de $53 \mathrm{Ha}, 44 \mathrm{Ha}$ corresponden a superficie forestal, y el resto ( $9 \mathrm{ha}$ ) es superficie agraria, principalmente almendro, olivo y cereales. Es justamente sobre esas terrazas de antiguos cultivos donde se han asentado las colecciones botánicas, que constituyen la actual zona ajardinada visitable.
El único acceso es a través de la A-7 de AlicanteAlcoy, en la salida Ibi Este, entrando por una rotonda que accede a un camino vecinal hacia el Paraje de San Pascual y a la Estación Biológica, existiendo carteles anunciadores desde la citada rotonda.

\section{PRINCIPALES ELEMENTOS E INSTALA- CIONES DEL JARDÍN BOTÁNICO}

La Estación Biológica cuenta con dos edificaciones principales, una antigua Masía, que hace las veces de recepción, despacho y zona residencial y otra que, sirve de laboratorio, banco de germoplasma, almacén y área de destilación de aceites esenciales. Este año se han ampliado estas dependencias con un nuevo almacén y una cochera. Además, cuenta con $300 \mathrm{~m} 2$ de invernaderos, dedicados a la producción de planta para el mantenimiento de las colecciones científicas e investigación, una Estación meteorológica automática y dos depósitos de agua (potable y de pluviales) que junto con una balsa estanque, proveen el agua de riego.

La estructura y denominación de las principales colecciones vegetales de la Estación Biológica Torretes es la que sigue:

A) Jardin Etnobotánico "Joan Pellicer"

1. Huerto de simples o rincón de las Plantas Medicinales

2. Rincón de las Especias Mediterráneas

3. Rincón de las Plantas Comestibles (cereales, legumbres, hortalizas, verduras, oleaginosas y plantas sacarinas), Forrajeras e Industriales (textiles, fibras, tintes y jabones)

7. Sendero de las Plantas Bulbosas: Orquideas y Narcisos endémicos mediterráneos

8. Salvietum, Colección monográfica del género Salvia y otras plantas aromáticas

9. Rosaleda "Pere Dot"

B) Jardin de las Culturas "Santiago Grisolía"

10. Rincón de las Grandes Culturas

11. Rincón de Trótula o Jardín de la Mujer

12. Rincón de las Plantas de los Santos 


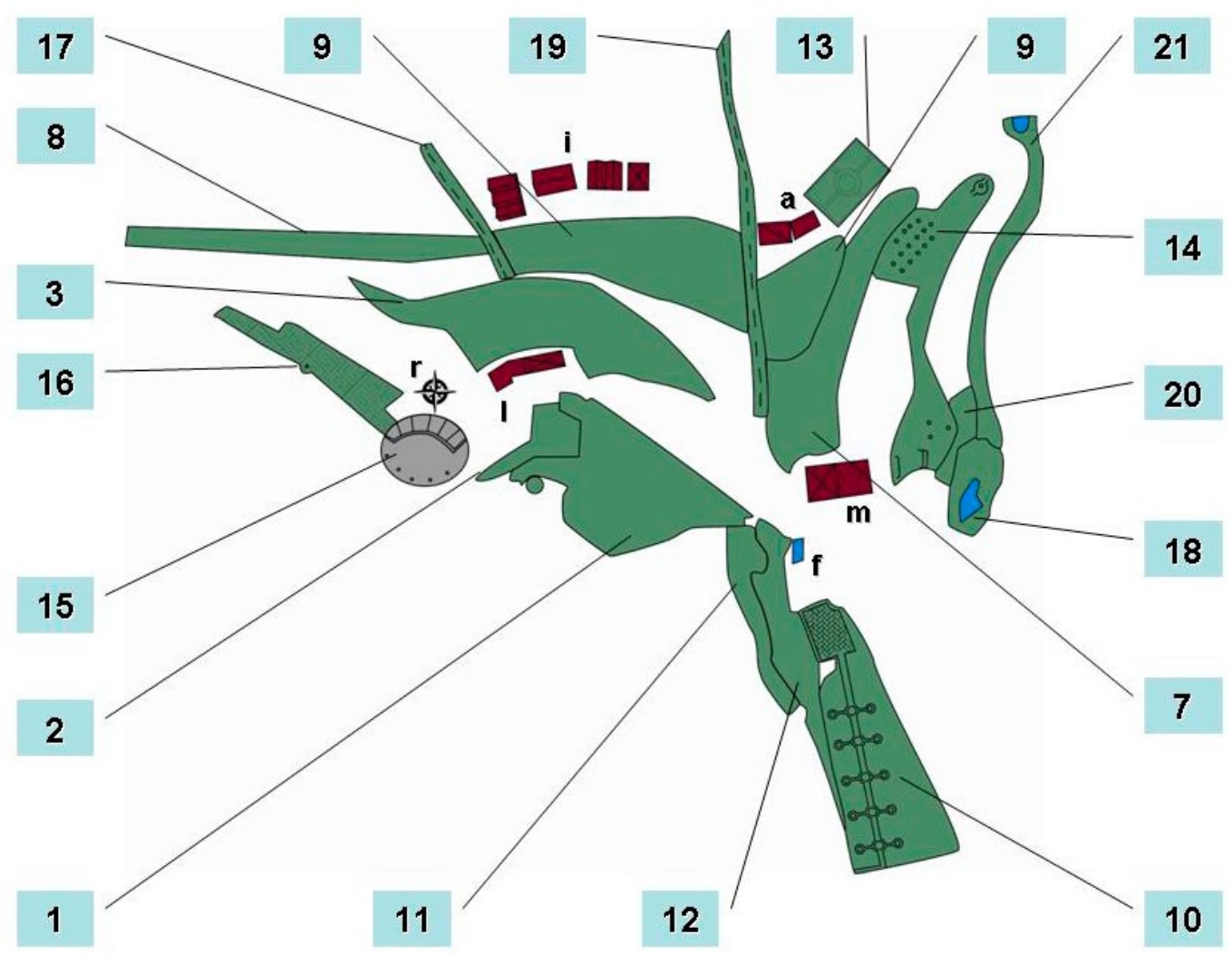

\section{Jardin Andalusi de Inb al Awan}

14. Rincón de las Plantas Mágicas, Tóxicas y Simbólicas (Rincón de Culpeper u Horóscopo Vegetal, Plantas de la Teoría de la Signatura, Plantas de los Cuatro Elementos y la Piedra Filosofal, Plantas del Soly de la Luna, Plantas de las brujas, Venenos vegetales)

C) Elementos conectivos y espacios naturales reforestados o ajardinados

\section{Replaceta y Pergola de Pio Font i Quer}

16. Laberinto Templario

17. Alameda de Andrés Laguna

18. Sauceda y Estanque Carlos Vicioso

19. Cuesta de Simón de Rojas Clemente

20. Rocalla alpina de Josias Braun Blanquet

21. Barranco de Enric Valor y Pozo de Paracelso

D) Vegetación natural, colecciones y cultivos agricolas, zonas de experimentación

Nota: algunas de estas unidades están en construcción en el momento actual.

\section{OTROS ELEMENTOS SINGULARES Y FIGURAS DE PROTECCIÓN}

Un antiguo horno de Cal, antiguos majanos (refugios para conejos) de piedra mampuesta, covachas de pastores y meleros, pozos y otras construcciones rurales, son parte del patrimonio etnográfico presente en la Estación. Como árboles singulares hay 2 ejemplares de pino carrasco (Pinus halepensis), recogidos en el Catálogo Valenciano de Árboles singulares.

Torretes se haya enclavado en la ladera Sur del Parque Natural del Carrascal de la Font Roja, y parte de la finca cae dentro de sus límites. Además las 20 ha superiores han sido incluidas en la Red Valenciana de Microreservas de Flora, y también una Reserva Voluntaria de Fauna y otra figura de Paraje Municipal Protegido, le afectan, desde el punto de vista de la Conservación. 
Esta pues dentro de un entorno natural, con mucha vegetación y cultivos preexistentes y que también forma parte de los valores visitables de la Estación. Muchas de las actuaciones realizadas, tienen por objeto incrementar la Biodiversidad del entorno y se ha hecho especial hincapié en mantener la vegetación arvense, mejorar los hábitats para la fauna y mantener los cultivos tradicionales con técnicas de Agricultura Biológica y variedades locales.
En este espacio, se trabaja, en la misma dirección del Instituto Universitario de Investigación CIBIO, creando un gran polo de atracción hacia la biodiversidad mediterránea y global, que permita mediante la transferencia de $\mathrm{I}+\mathrm{D}+\mathrm{i}$ trazar un puente entre la excelencia y la divulgación científica, para contribuir al desarrollo y a la conservación de nuestros recursos naturales. 